V. Thiagarajan

T. Barts

S. Kurennoy

\title{
Calculation of the Coupling Impedances of Holes and Slots \\ on the Liner Using MAFIA and Scaling
}

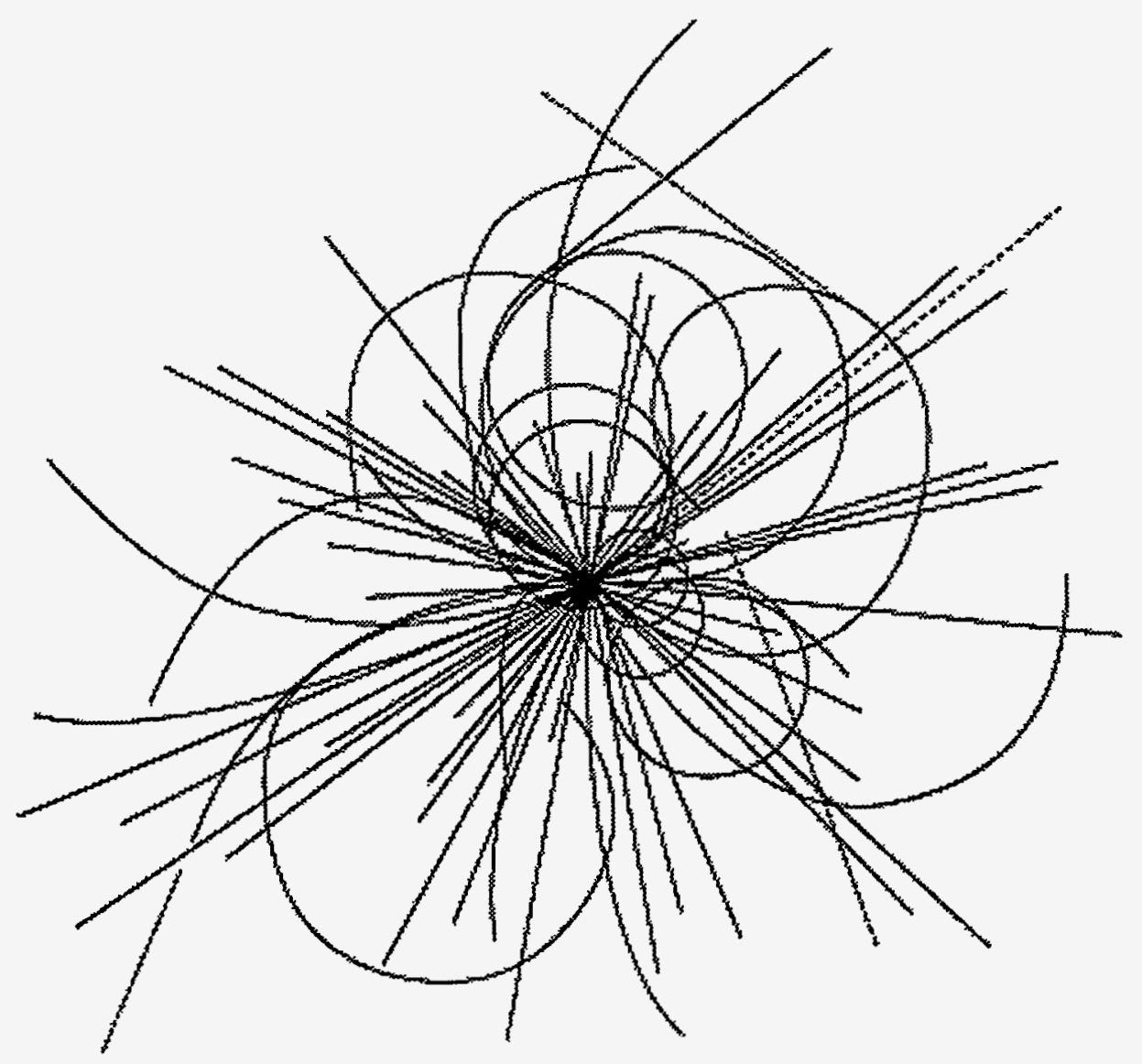

W. Chou 


\section{Disclaimer Notice}

This report was prepared as an account of work sponsored by an agency of the United States Government. Neither the United States Government or any agency thereof, nor any of their employees, makes any warranty, express or implied, or assumes any legal liability or responsibility for the accuracy, completeness, or usefulness of any information, apparatus, product, or process disclosed, or represents that its use would not intringe privately owned rights. Reference herein to any specific commercial product, process, or service by trade name, trademark, manufacturer, or otherwise, does not necessarily constitute or imply its endorsement, recommendation, or favoring by the United States Government or any agency thereot. The views and opinions of authors expressed herein do not necessarily state or reflyct those of the United States Govemment or any agency thereot.

Superconducting Super Collider Laboratory is an equal opportunity employer. 


\section{DISCLAIMER}

Portions of this document may be illegible in electronic image products. Images are produced from the best available original document. 
SSCL-650

\title{
Calculation of the Coupling Impedances of Holes and Slots on the Liner Using MAFIA and Scaling
}

\author{
V. Thiagarajan, T. Barts, S. Kurennoy, and W. Chou \\ Superconducting Super Collider Laboratory* \\ 2550 Beckleymeade Avenue \\ Dallas, Texas 75237
}

November 1993

DISTHZIBUTION OF THIS DOCUMENT IS UNLIMITED

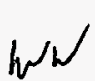

\footnotetext{
* Operated by the Universities Research Association, Inc., for the U.S. Department of Energy under Contract No. DE-AC35-89ER40486.
} 


\title{
Calculation of the Coupling Impedances of Holes and Slots on the Liner Using MAFIA and Scaling
}

\author{
V. Thiagarajan, T. Barts, S. Kurennoy, and W. Chou
}

\begin{abstract}
The location of a liner inside the beam tube is one of the options considered for the Super Colliders (SSC-Superconducting Super Collider and LHC-Large Hadron Collider). The liner could serve as a synchrotron radiation intercept and also help enhance the vacuum. A definite distribution of holes or slots is required to be located on the liner for pumping out the desorbing gases. There will be wake fields propagating within the liner due to diffraction at discontinuities (holes, slots, bellows, etc.) following the incident beam fields. The effect of these wake fields can be minimized by adopting the least number of pumping holes/slots required and through an optimal choice of hole/slot shape and size. The effect of the wake fields on the beam may be expressed through coupling impedances defined proportional to the corresponding forces integrated through distance per unit charge. It is necessary to compute the impedance of holes and slots and determine the scaling of the impedance with the dimensions of the hole/slot and the liner, in order to optimize the choice of pumping holes/slots. The coupling impedances of slots and holes have been calculated here using the code MAFIA and the scaling assessed. The results compare favorably with existing analytical results.
\end{abstract}




\subsection{INTRODUCTION}

The introduction of a liner inside the beam tubes of super colliders (the Superconducting Super Collider-SSC, and the Large Hadron Collider-LHC) serves many purposes. The liner could serve as a synchrotron radiation intercept. If the liner could be maintained at a high temperature, the incident energy could be removed efficiently. The discontinuities in the liner will result in wake fields propagating inside the liner. These fields will act on successive bunches and could result in bunch lengthening, instabilities and emittance growth. The liner will help enhance the vacuum; one needs to provide an appropriate number and distribution of slots/holes on the surface of the liner for removing the desorbing gases. We have the advantage of optimizing and minimizing the number of holes and thus minimize the effect of the wake fields on the beam.

The effect of the wake fields on the beam bunches may be expressed quantitatively through the longitudinal or transverse coupling impedances of the slots or holes, which are defined proportional to the integrated force (longitudinal or transverse) per unit charge. ${ }^{1-4}$ The coupling impedance of round holes on the liner of LHC and SSC have been studied analytically by Gluckstern ${ }^{5}$ and Kurennoy ${ }^{3}$ for low frequencies, where the dimension of the hole is much smaller than the wave length of the incident field. Kurennoy ${ }^{6}$ has obtained a formula for the coupling impedance of slots using the expressions of magnetic and electric polarizabilities from McDonald. ${ }^{7,8}$ We have computed here the coupling impedances of slots and holes of various dimensions using the code MAFIA. ${ }^{9}$ We have obtained scaling relations for the coupling impedances and compared them with the values obtained using expressions from Gluckstern and Kurennoy. ${ }^{3,5,6}$

\subsection{DESCRIPTION OF THE PROBLEM}

A schematic of the beam pipe and the liner is shown in Figure 1. The liner of inner radius $a$ and thickness $\Delta$ is located inside the beam tube of radius $b$. A slot of length $w$ and width $d$ is located on the liner. The center of the slot is situated at $z=0.0$. In the case of round holes we will denote the diameter of the hole by $d$. The coordinate system is shown in Figure 1. The longitudinal impedance is defined as follows: ${ }^{3}$

$$
Z(\omega)=-\frac{1}{q} \int_{-\infty}^{\infty} E_{z}(r=0, \theta=0) e^{j k z} d z
$$

where $k=\frac{\omega}{c}$. 

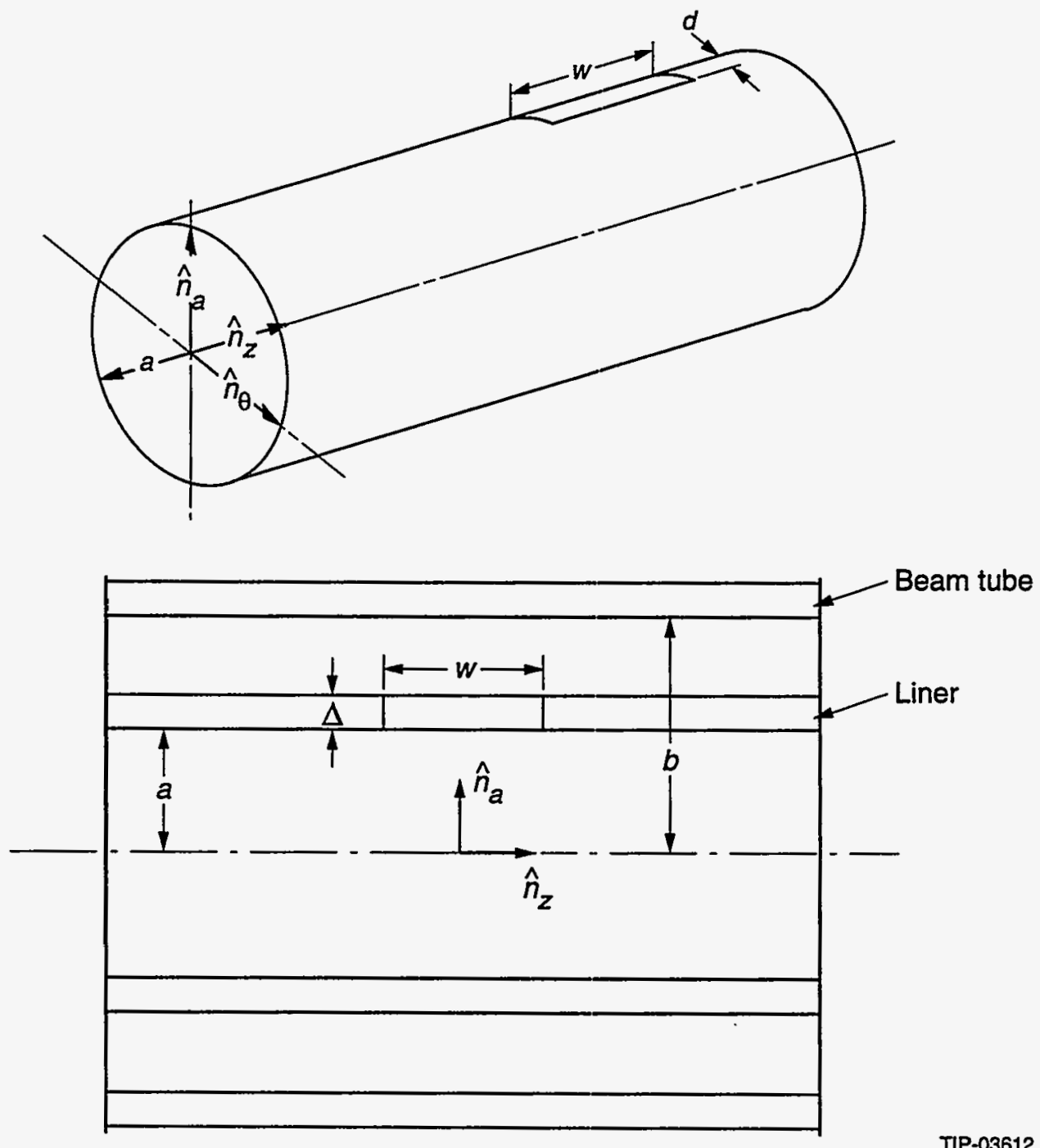

Figure 1. Slot details and coordinate system.

The calculations for wake fields were done using Version $31 f$ of the code T3310 in the MAFIA group (see Appendix for sample input). T3310 was run exclusively on an IBM 560 workstation. The impedances were calculated on a Sun SPARC station with the in-house post-processor MW2FFT designed to read the wake fields, sigma, beta, offsets, length and time variables for calculating the $Z$ directly from the T3310 print file with the T3310 input file prepended. The dataset name and the number of holes is entered interactively and then the impedance is calculated and the output stored for plotting. Details of calculation of the impedance from MAFIA output can be found in Reference 11.

An example of the geometry for the cases run is shown in Figure 1(a). The inner radius of the liner $a=1.65 \mathrm{~cm}$, the thickness of the liner $\Delta=1 \mathrm{~mm}$, the radius of the beam tube $b=2.15 \mathrm{~cm}$ and the total length of the structure is $20 \mathrm{~cm}$. The mesh size was $0.5 \mathrm{~mm}$ in 
all cases. The beam modeled for all cases was Gaussian with a $\sigma=0.25 \mathrm{~cm}$ extending up to $5 \sigma$ 's in the positive and negative $z$ directions. In the case of the transverse impedance, the beam was offset $1 \mathrm{~mm}$ from the axis in the positive $\mathrm{x}$ and $\mathrm{y}$ directions. In the case of the longitudinal wakes alone, one quarter of the structure was modeled and the length increased to $50 \mathrm{~cm}$. For the cases where the radius $a$ of the liner was varied, the thickness $\Delta$ was maintained at $1 \mathrm{~mm}$ and the air gap between the liner and the beam tube was maintained at $4 \mathrm{~mm}$.

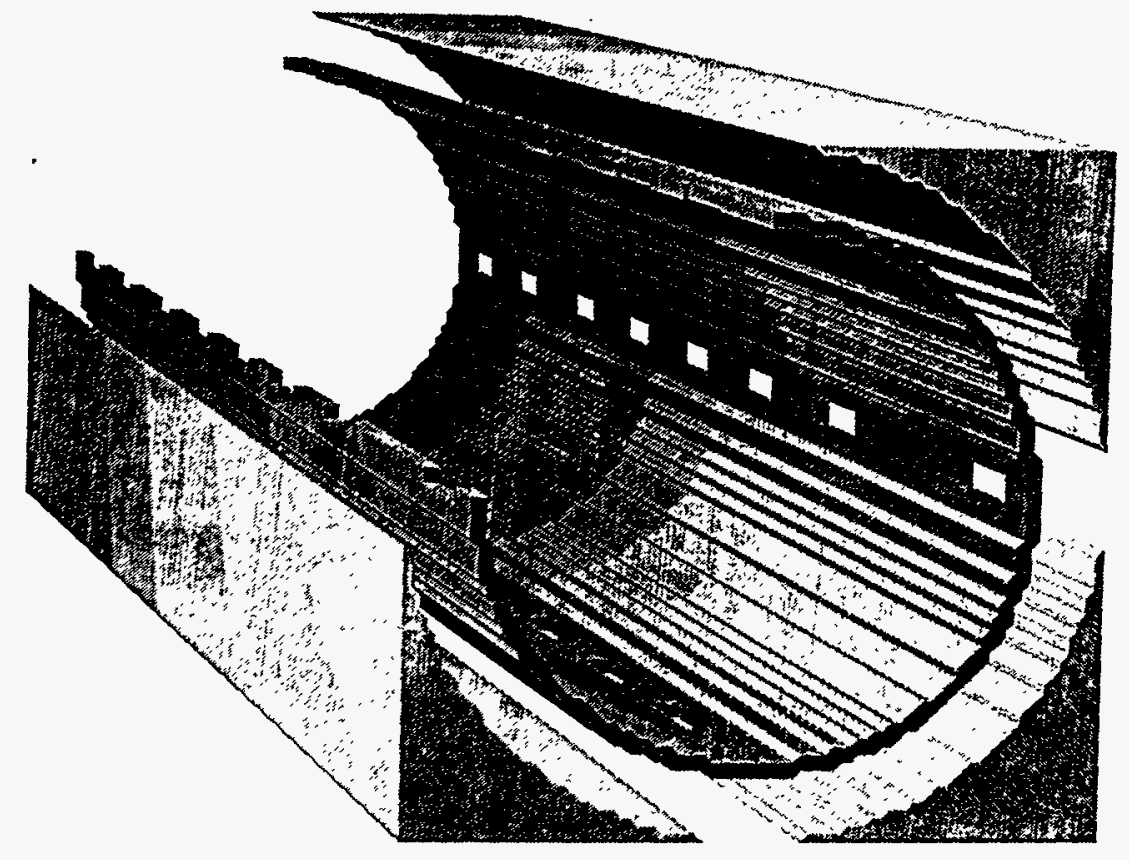

Figure 1(a). 3D plot of the slot distribution, 20-cm liner with $322 \times 12$ slots, randomly distributed.

All the wake fields were calculated with irregular distributions of holes or slots. For the case of longitudinal wake fields and impedances 184 holes were modeled except for the $2 \times 12 \mathrm{~mm}$ and $2 \times 20 \mathrm{~mm}$ cases, where only 60 slots were simulated. For the transverse wake fields and impedances, 80 openings were simulated for all but the cases with the two longest slots where only 32 slots were used. The strategy was to incorporate as many openings as possible for the strongest possible signal with the length in $z$ as long as could be accommodated within the limitations of the code.

\subsection{The Longitudinal Coupling Impedance of Round Holes}

The expression for the longitudinal coupling impedance of holes at low frequencies obtained by Gluckstern and Kurennoy ${ }^{5,6}$ is:

$$
Z=\frac{j Z_{0} k d^{3}}{6 \pi^{2} a^{2}}
$$


where, $Z_{0}=120 \pi \Omega$ is the impedance of free space. In order to check the variation of the longitudinal impedance of holes with the radius of the liner $a$, computations were carried with MAFIA, with randomly distributed 4-mm holes with the liner radii of 1.35 , 1.65 and $1.95 \mathrm{~cm}$. The impedance varies linearly with the frequency in the range $0-5 \mathrm{GHz}$ (Figure 2). The impedances at a frequency of $5.27 \mathrm{GHz}$ are shown in Table 1. The values in the fourth column of Table 1 calculated with a $a^{-2}$ dependence compare favorably with the values in the third column obtained from MAFIA. The impedance results for round holes are shown in Figure 3 and Table 2. It should be remembered that the round hole is approximated by a polygon with maximum number of sides possible within the limitations of the code and the computer memory. The impedance is again found to vary linearly with the frequency in the range 0 to $5 \mathrm{GHz}$. The impedance was scaled with a $d^{3}$ dependence with the impedance of the $3-\mathrm{mm}$ hole as a reference and the resulting values are shown in column 4 of Table 2 . These compare favorably with the MAFIA results in column 3 . The values in column 4 were obtained with the Gluckstern/Kurennoy formula, Eq. (2) and are about two times higher. The difference can be explained by the fact that Eq. (2) is valid only for a very thin wall. The thickness corrections have been calculated for round holes by Gluckstern, ${ }^{5}$ and they reduce the impedance values from those for the case of a thin wall. The last column of Table 2 shows the impedance using Eq. (2) with thickness corrections applied. The MAFIA results are in good agreement with these corrected impedance values. Also shown in Figure 3 are experimental values of the longitudinal coupling impedance for a 3 -mm hole. ${ }^{10}$ These values are found to be marginally higher than those obtained from MAFIA computations.

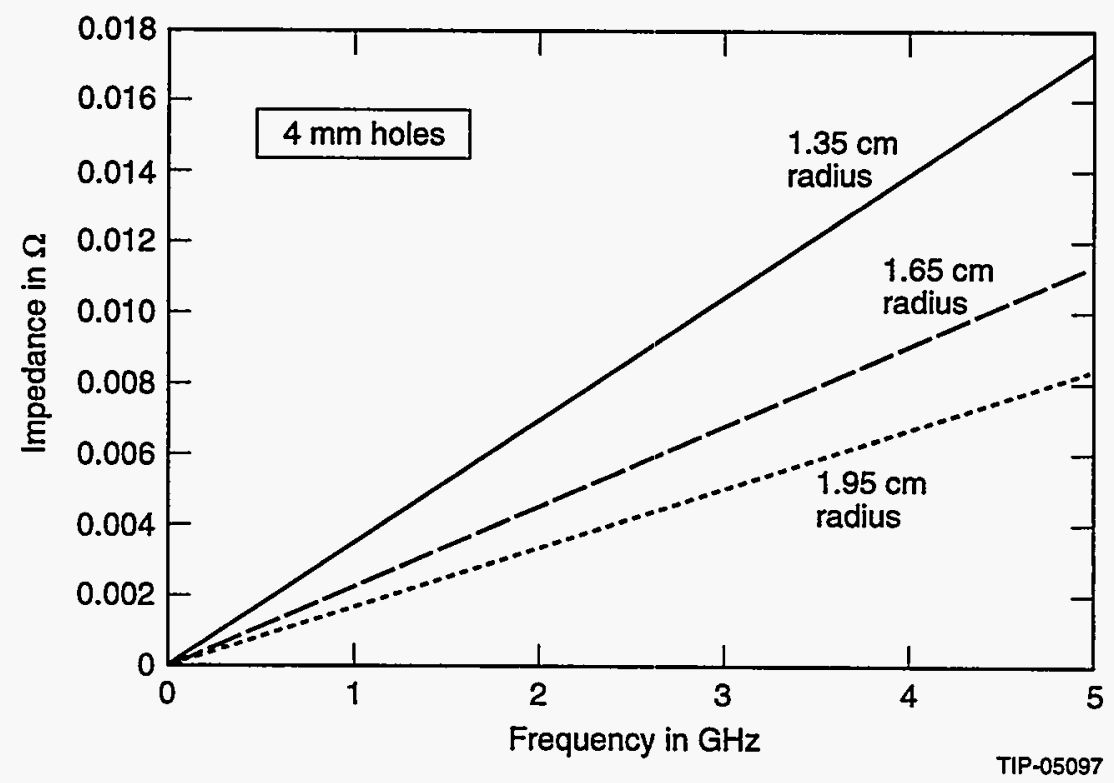

Figure 2. Variation of the longitudinal impedance with the liner radius. 
Table 1. Variation of the Longitudinal Impedance with the Radius of the Liner.

\begin{tabular}{|c|c|c|c|}
\hline $\begin{array}{c}\text { Liner I.D. } \\
(\mathrm{cm})\end{array}$ & $\begin{array}{c}\text { Frequency } \\
(\mathrm{GHz})\end{array}$ & $\begin{array}{c}\text { Impedance } \\
(\mathrm{mohms})\end{array}$ & $\begin{array}{c}Z=Z_{1.35}\left(\frac{1.35}{d}\right)^{2} \\
(\mathrm{mohms})\end{array}$ \\
\hline 1.35 & 5.270 & 18.32 & 18.32 \\
1.65 & 5.270 & 12.02 & 12.26 \\
1.95 & 5.270 & 8.936 & 8.780 \\
\hline
\end{tabular}

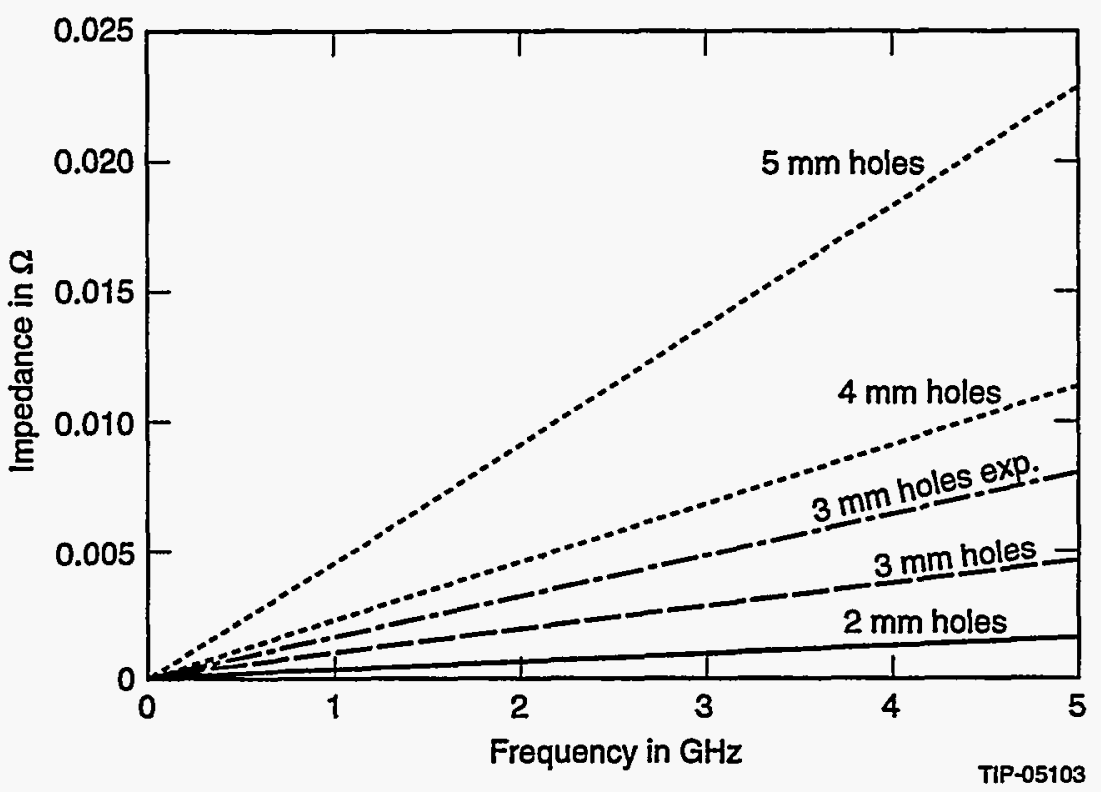

Figure 3. Longitudinal coupling impedance of holes.

Table 2. Longitudinal Coupling Impedance of Holes.

\begin{tabular}{|c|c|c|c|c|c|}
\hline $\begin{array}{c}\text { Hole Dia. } \\
\text { (mm) }\end{array}$ & $\begin{array}{l}\text { Freq. } \\
\text { (GHz) }\end{array}$ & $\begin{array}{l}\text { Imped. } \\
\text { (mohms) }\end{array}$ & $\begin{array}{c}Z=Z_{3 \mathrm{~mm}}\left(\frac{d}{3}\right)^{3} \\
(\mathrm{mohms})\end{array}$ & $\begin{array}{l}\text { Imped. } \\
\text { Eq. (2) } \\
\text { (mohms) }\end{array}$ & $\begin{array}{c}\text { Corrected } \\
\text { Imped. } \\
(\mathrm{mohms})\end{array}$ \\
\hline 2 & 4.977 & 1.560 & 1.391 & 2.447 & 1.390 \\
\hline 3 & 4.977 & 4.696 & 4.696 & 8.260 & 4.870 \\
\hline 4 & 4.977 & 11.38 & 11.13 & 19.58 & 12.100 \\
\hline 5 & 4.977 & 22.76 & 21.74 & 38.24 & 25.200 \\
\hline
\end{tabular}

\subsection{The Longitudinal Coupling Impedance of Slots}

Kurennoy ${ }^{6}$ has obtained the following analytical expressions for the longitudinal coupling impedance of a slot. From the general expressions of References 3, 5:

$$
Z=j Z_{0} k \frac{\left(\alpha_{m}+\alpha_{e}\right)}{4 \pi^{2} a^{2}}
$$


using the magnetic and electric polarizabilities $\alpha_{m}, \alpha_{e}$ from $\mathrm{McDonald},{ }^{7,8}$ the longitudinal coupling impedance of a rectangular slot with length $w$ and depth $d$ for the case $w>d$ is

$$
Z=j Z_{0} k \frac{d^{3}(0.1814-0.0344 d / w)}{4 \pi^{2} a^{2}} .
$$

When the slot ends are rounded the expression for impedance becomes

$$
Z=j Z_{0} k \frac{d^{3}(0.1334-0.0500 d / w)}{4 \pi^{2} a^{2}} .
$$

For the case of a rectangular slot with $d>w$, the following equations apply.

$$
Z=j Z_{0} k \frac{d^{3}}{4 \pi^{2} a^{2}}\left(\frac{0.132}{\ln \left(1+0.66 \frac{d}{w}\right)}-\frac{\pi}{16}\left(\frac{w}{d}\right)^{2}\left(1-0.57 \frac{w}{d}+0.14\left(\frac{w}{d}\right)^{2}\right)\right) .
$$

For a slot with rounded ends and with $d>w$,

$$
Z=j Z_{0} k \frac{d^{3}}{4 \pi^{2} a^{2}}\left(\frac{0.187+0.052 \frac{w}{d}\left(1-\frac{w}{d}\right)}{\ln \left(1+2.12 \frac{w}{d}\right)}-\frac{\pi}{16}\left(\frac{w}{d}\right)^{2}\left(1-0.77 \frac{w}{d}+0.19\left(\frac{w}{d}\right)^{2}\right)\right) .
$$

MAFIA computations were carried out for various slots of widths $w$ and depth $d$. The results for $d=2 \mathrm{~mm}$ and $w=2,6,12$, and $20 \mathrm{~mm}$ are shown in Figure 4. The impedance is almost independent of the width $w$ and this favorably compares with the predictions of Eqs. (4) and (5) which show very weak dependence on $w$. The impedances for $w=2 \mathrm{~mm}$ and $d=2,3,4$, and $5 \mathrm{~mm}$ are shown in Figure 5 and Table 3. Shown in column 4 of Table 3 is the scaling exponent $n$ obtained from $Z=Z_{3} \mathrm{~mm}\left(\frac{d}{3}\right)^{n}$. Column 5 gives the values of the impedance calculated using Eq. (6). These values are about two times the values from MAFIA computations. This difference can again be explained by thickness corrections which are not included in Eq. (6). While the impedance is almost independent of $w$, it is found to vary as $d^{n}$ with $n$ being approximately equal to 2.8 , as evidenced by the values in column 4 . The impedances for slots with $w=4 \mathrm{~mm}$ and $d=1,2$, and $4 \mathrm{~mm}$ are shown in Figure 5 and Table 4. The impedances from Eq. (4) are again higher than the MAFIA results. Column 4 of Table 4 gives the scaling exponent obtained from $Z=Z_{2} \mathrm{~mm}\left(\frac{d}{2}\right)^{n}$. The exponent is approximately 3.0 for $w=4 \mathrm{~mm}$.

The effect of rounding the edges of slots is shown in Figure 6 using slots of $d=2$, $w=6 \mathrm{~mm}$ and $d=2, w=12 \mathrm{~mm}$. The rounding of the edges of slots results in a decrease of impedance by a factor of about 1.3 and this is also born out by Eqs. (4) and (5). 


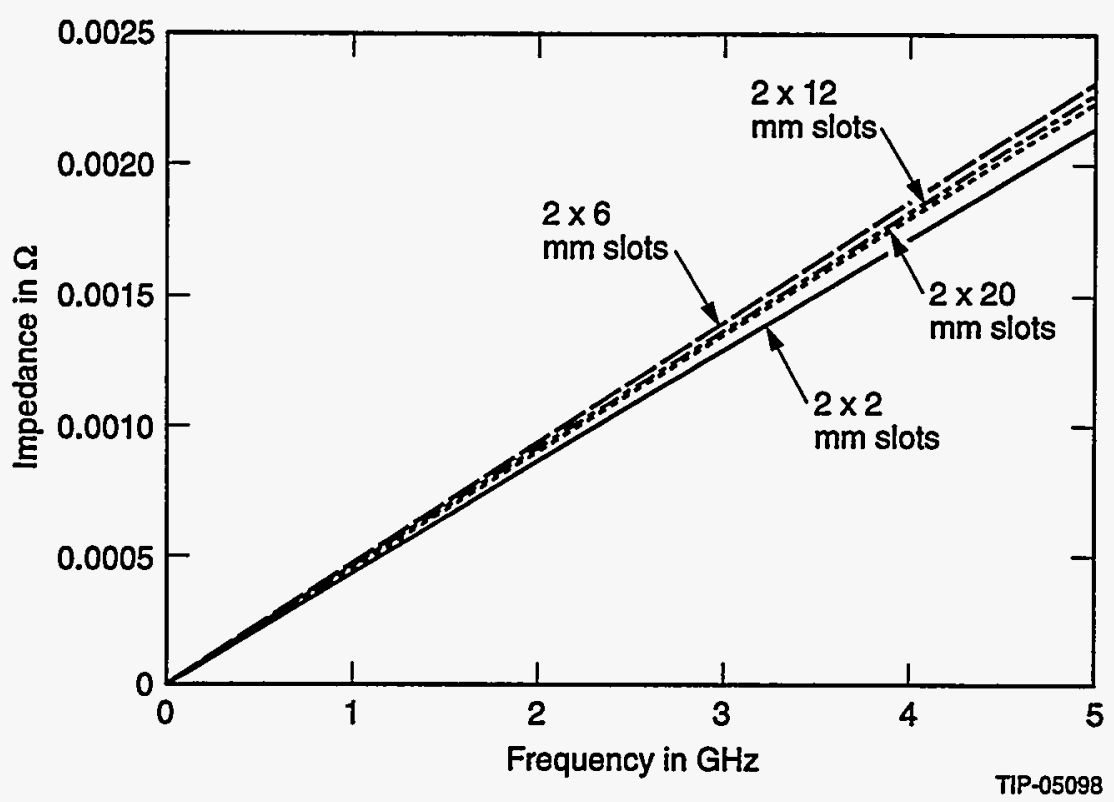

Figure 4. Longitudinal impedance of slots with various widths, $w$.

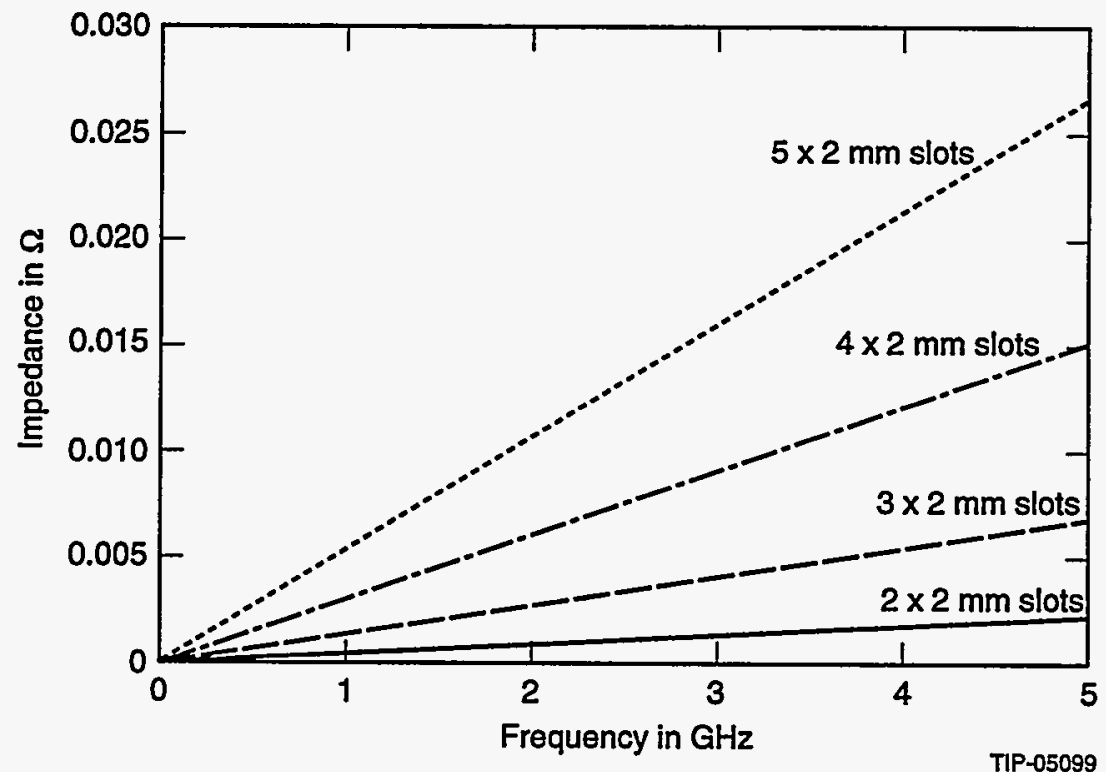

Figure 5. Longitudinal coupling impedance of slots with various depths, $d$. 
Table 3. Longitudinal Coupling Impedance of Slots $(w=2 \mathrm{~mm})$.

\begin{tabular}{|c|c|c|c|c|}
\hline $\begin{array}{c}\text { Slot Dimns. } \\
(\mathrm{mm})\end{array}$ & $\begin{array}{c}\text { Freq. } \\
(\mathrm{GHz})\end{array}$ & $\begin{array}{c}\text { Imped. } \\
(\mathrm{mohms})\end{array}$ & $n$ & $\begin{array}{c}\text { Imped. Eq. (6) } \\
\text { (mohms) }\end{array}$ \\
\hline $2 \times 2$ & 4.977 & 2.139 & 2.845 & 4.360 \\
$3 \times 2$ & 4.977 & 6.779 & & 13.030 \\
$4 \times 2$ & 4.977 & 14.98 & 2.756 & 28.070 \\
$5 \times 2$ & 4.977 & 26.46 & 2.666 & 50.270 \\
\hline
\end{tabular}

Table 4. Longitudinal Coupling Impedance of Slots $(w=4 \mathrm{~mm})$.

\begin{tabular}{|c|c|c|c|c|}
\hline $\begin{array}{c}\text { Slot Dimns. } \\
(\mathrm{mm})\end{array}$ & $\begin{array}{c}\text { Freq. } \\
(\mathrm{GHz})\end{array}$ & $\begin{array}{c}\text { Imped. } \\
(\mathrm{mohms})\end{array}$ & $n$ & $\begin{array}{c}\text { Imped. Eq. (4) } \\
\text { (mohms) }\end{array}$ \\
\hline $1 \times 4$ & 4.977 & 2.261 & 3.35 & 6.314 \\
$2 \times 4$ & 4.977 & 2.308 & & 4.803 \\
$4 \times 4$ & 4.977 & 18.53 & 3.005 & 34.40 \\
\hline
\end{tabular}

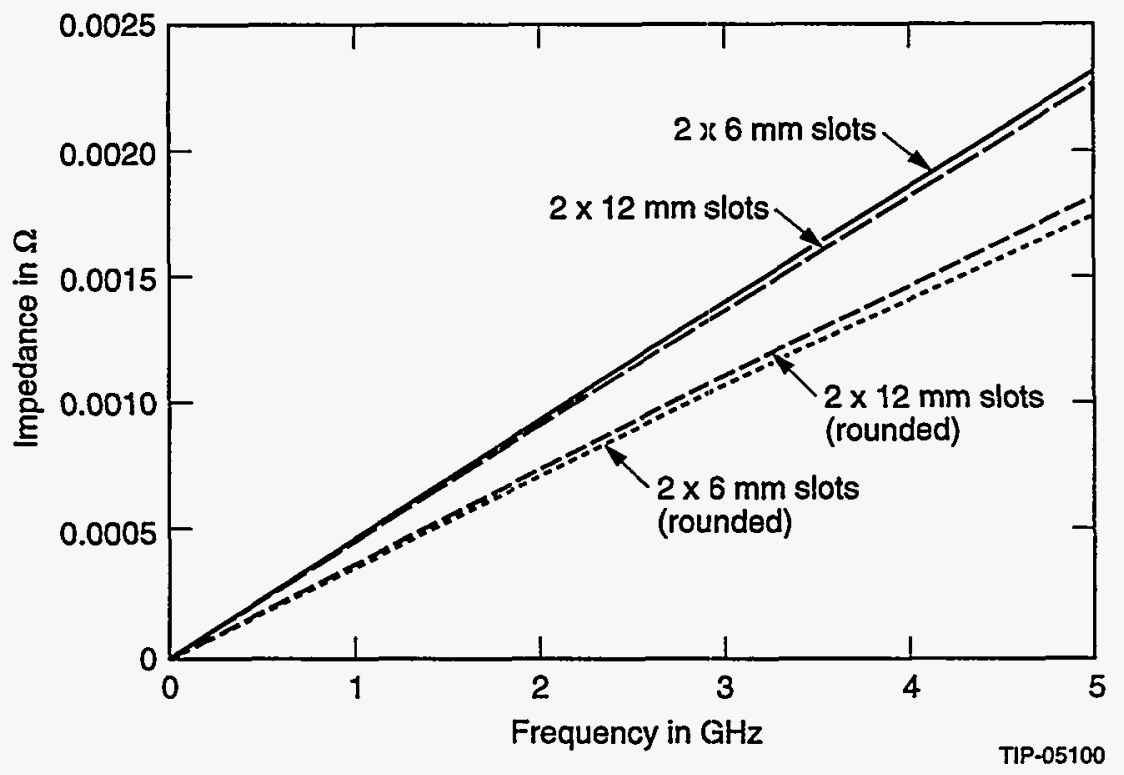

Figure 6. Longitudinal impedance for rectangular and rounded slots.

\subsection{The Transverse Coupling Impedance of Slots}

The transverse coupling impedance is defined as follows: ${ }^{3}$

$$
\begin{gathered}
\vec{Z}_{t}(\omega, \vec{r}, \vec{r})=\lim _{r \rightarrow 0} \frac{j}{q r} \int_{-\infty}^{\infty} d z e^{j k z}\left(\hat{n}_{a}\left(E_{r}-Z_{0} H_{\phi}\right)(r, \phi, z ; \omega)\right. \\
\left.+\hat{n}_{\phi}\left(E_{\phi}-Z_{0} H_{r}\right)(r, \phi, z ; \omega)\right) .
\end{gathered}
$$


The transverse impedance per round hole reduces from Eq. (8) to

$$
Z_{t}=j \frac{Z_{0}}{24 \pi^{2}} \frac{d^{3}}{a^{4}}
$$

In the case of slots with $w>d$ Eq. (8) reduces to

$$
Z_{t}=j \frac{Z_{0}}{2 \pi^{2}} \frac{d^{3}}{a^{4}}\left(0.1814-0.0344 \frac{d}{w}\right) .
$$

The transverse impedances (per hole or slot) computed from MAFIA for holes and slots are shown in Figures 7 and 8.

The $d^{3}$ dependence and $k^{0}$ dependence indicated by Eqs. (8) and (9) are corroborated by the MAFIA results.

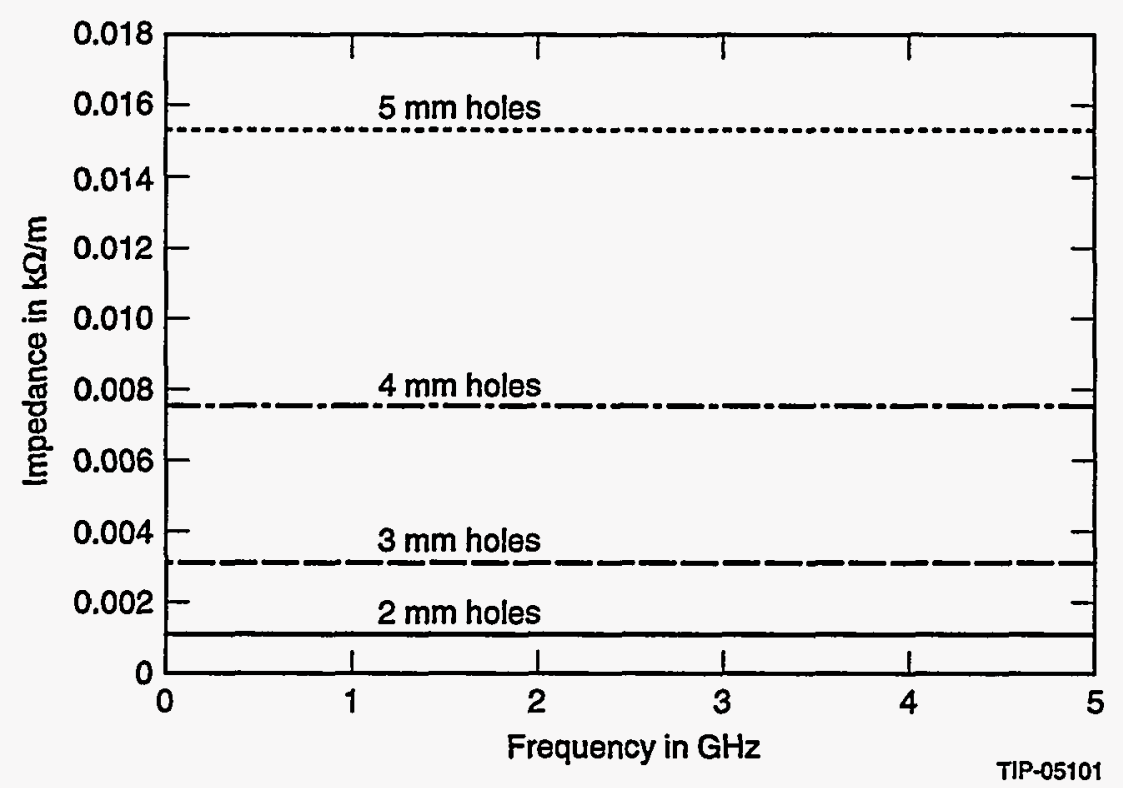

Figure 7. Transverse impedance of holes. 

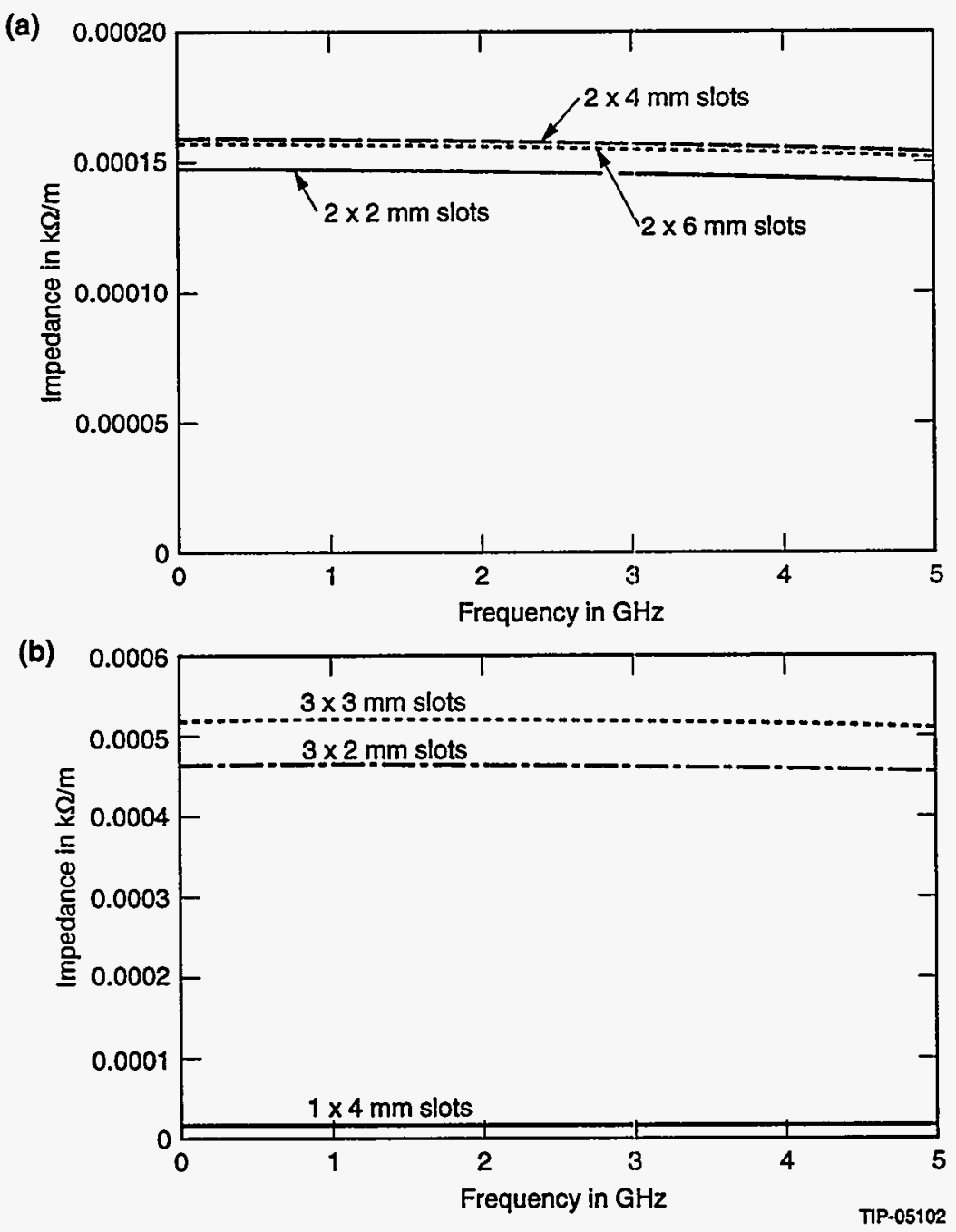

Figure 8. (a) Transverse impedance of slots. (b) Transverse impedance of slots.

\subsection{CONCLUSIONS}

MAFIA computations were carried out for the longitudinal and transverse coupling impedances of slots/holes on the liners of super colliders. The impedances of round holes scale as $d^{3}$ and $a^{-2}$. The impedances of slots scale approximately as $d^{2.8}$ for $w=2 \mathrm{~mm}$ and $d^{3.0}$ for $w=4 \mathrm{~mm}$ and $w^{0}$. Rounding the edges of slots results in a further decrease in impedance. One should obviously choose randomly placed slots of least $d$ and maximal $w$ and also round the edges of the slots, if this does not pose fabrication problems. The total number of slots will be determined from the required pumping area. There is good agreement between MAFIA calculations and analytical results with thickness corrections taken into account. 


\section{ACKNOWLEDGEMENTS}

The authors acknowledge encouragement from Michael J. Syphers and William C. Turner. 



\section{REFERENCES}

1. B. Zotter, "Electromagnetic Fields: Impedances and Wakes," AIP Conference Proceedings 153, Physics of Particle Accelerators, American Institute of Physics, (1987).

2. A.W. Chao, "Coherent Instabilities of a Relativistic Bunched Beam," Physics of High Energy Particle Accelerators, SLAC Summer School, 1982, AIP Conference Proceedings, No. 105, (1983).

3. S.S. Kurennoy, "On the Coupling Impedance of a Hole or a Slot," CERN SL/91-29 (AP), 1991; Particle Accelerators, v. 39, p. 1 (1992).

4. S.A. Heifets and S.A. Kheifets, "Coupling Impedance in Modern Accelerators," Reviews of Modern Physics, Vol. 63, No. 3, July, 1991.

5. R.L. Gluckstern, "Coupling Impedance of a Hole in a Thick Wall Beam Pipe," CERN SL/91 (AP), November 1991; Physical Review A, v. 46, p. 1106 (1992).

6. S.S. Kurennoy, "Pumping Slots: Coupling Impedance Calculations and Estimates," SSCL-636, Superconducting Super Collider Laboratory, Dallas, Texas, August, 1993.

7. N.A. McDonald, "Polynomial Approximations for the Transverse Magnetic Polarizabilities of Some Small Apertures," IEEE Transactions on Microwave Theory and Techniques, Vol. MTT-35, No.1, p. 20, January, 1987.

8. N.A. McDonald, "Polynomial Approximations for the Electric Polarizabilities of Some Small Apertures," IEEE Transactions on Microwave Theory and Techniques, Vol. MTT-33, No. 11, p. 1146, November, 1985.

9. MAFIA, Release 3.1, The MAFIA Collaboration, October, 1991, distributed by CST Gesellschaft fur Computer-Simulationtechnik m.b.h., CST Gmbh, Lauteschlagerstr .38, D6100, Darmstadt, Germany.

10. E. Ruiz et al., "Beam Coupling Impedance Measurements and Simulations of a Beam Pipe Liner with Pumping Holes or Slots," Paper Pa 61, IEEE PAC 93, Washington. D.C., 1993 (also, SSCL-Preprint-351).

11. W. Chou, T. Barts, "Wakefield and Impedance Studies of a Liner Using MAFIA," SSCLPreprint-204, SSC Laboratory, Dallas, TX, March, 1993. 



\title{
APPENDIX
}

\author{
Input File
}



Following is the input file for m310 for calculating the longitudinal wakes for $602 \times 12$ slots using a quarter geometry.

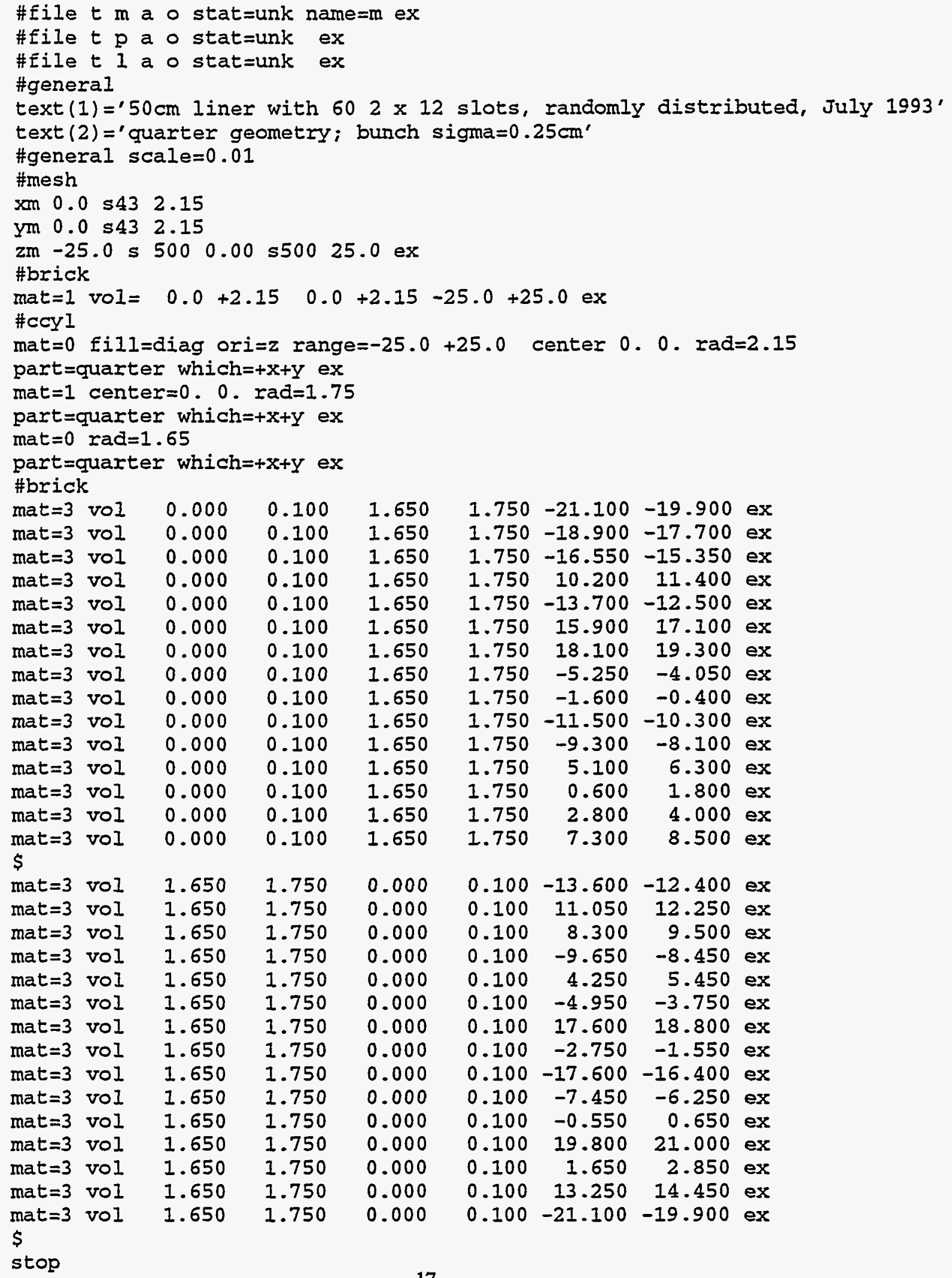


Following is the input file for $t 3310$ for calculating the longitudinal wakes for $602 \times 12$ slots using a quartergeometry.

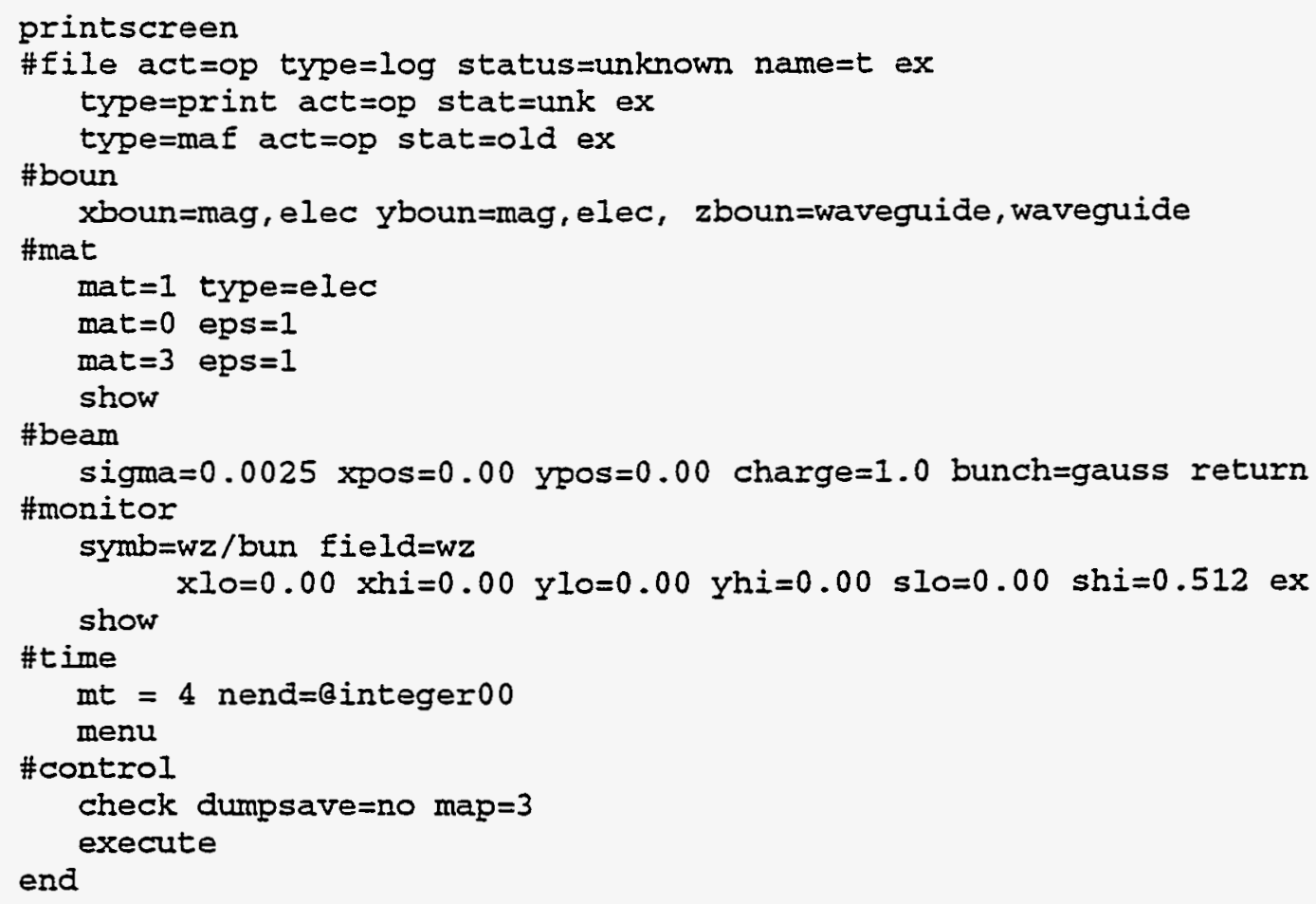


Following is the input file for p310 for calculating the longitudinal wakes for $602 \times 12$ slots using the whole geometry.

\#file act $=o p$ type=log status=unknown name=p ex type $=$ print act $=o p$ stat $=u n k$ ex type $=$ maf act $=o p$ stat $=01 d$ ex \#Iist sym=general ex items $=1024$ symb=wz/bun ex stop 
Following is the input file for $\mathrm{m} 310$ for calculating the transverse wakes for $322 \times 12$ slots using the whole geometry.

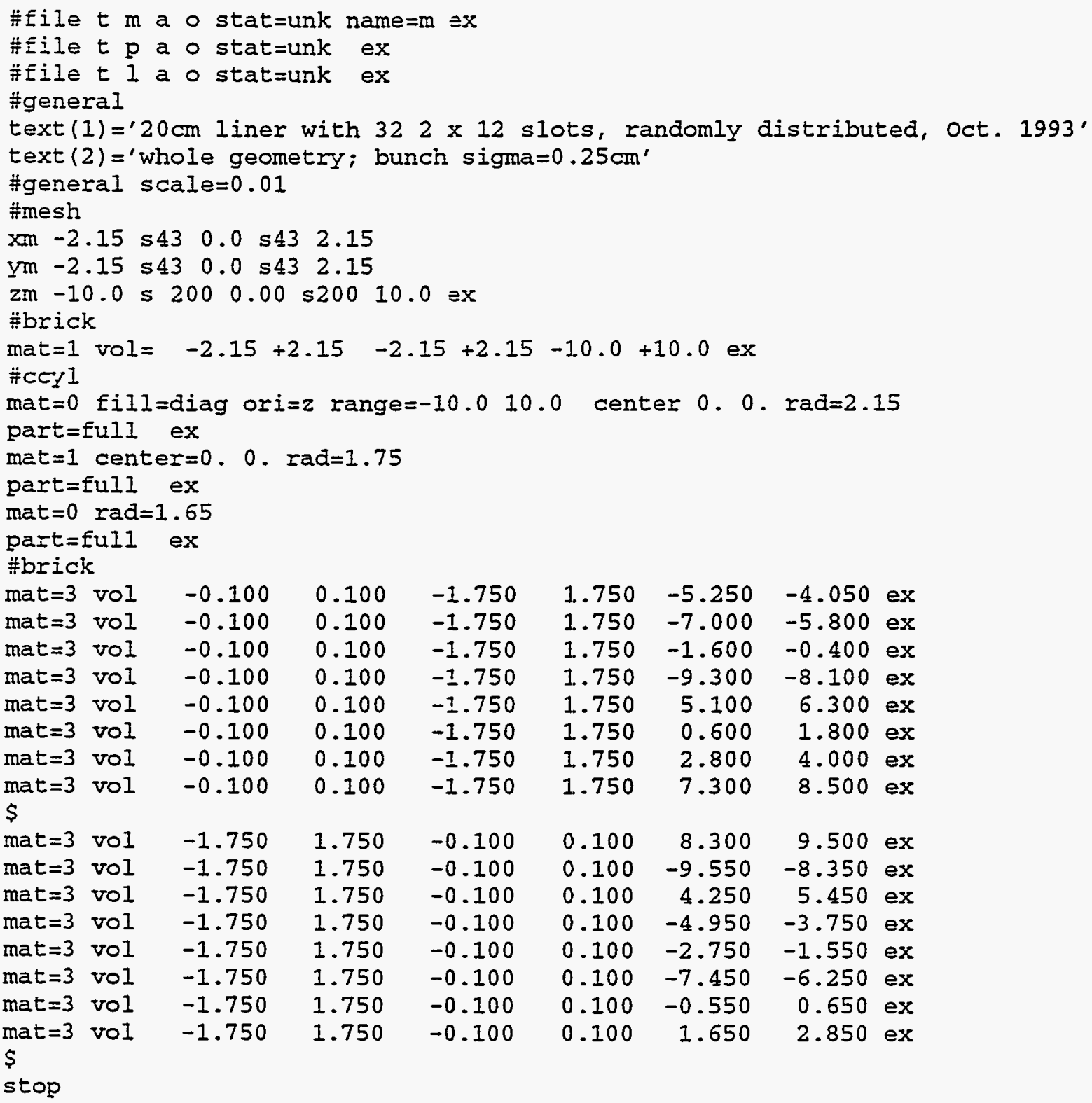


Following is the input file for $t 3310$ for calculating the transverse wakes for $322 \times 12$ slots using the whole geometry.

printscreen

\#file act $=0 p$ type $=\log$ status=unknown name $=t$ ex type $=$ print act $=o p$ stat $=u n k$ ex type=maf act $=0 p$ stat $=0 I d$ ex

\#boun \#mat xboun=elec, elec yboun=elec,elec, zboun=waveguide, waveguide 